\title{
Improving cancer immunotherapy by targeting tumor-induced immune suppression
}

Trina J. Stewart* and Mark J. Smyth

Cancer Immunology Research Program

Peter MacCallum Cancer Centre

St Andrews Place, East Melbourne.

Victoria, Australia. 3002.

Email: trina.stewart@ petermac.org; mark.smyth@ petermac.org

${ }^{*}$ Corresponding author

Keywords: Immune suppression, Tumor immunology, Immunotherapy, MDSC, Inhibitory cytokines

\begin{abstract}
Heading 1]
The status of a host's immune response influences both the development and progression of a malignancy such that immune responses can have both pro- and anti-tumorigenic effects. Cancer immunotherapy is a form of treatment that aims to improve the ability of a cancer-bearing individual to reject the tumor immunologically. However, antitumor immunity elicited by the host or by immunotherapeutic strategies, can be actively attenuated by mechanisms that limit the strength and/or duration of immune responses, including the presence of immunoregulatory cell types or the production of immunosuppressive factors. As our knowledge of tumor-induced immune suppression increases it has become obvious that these mechanisms are probably a major barrier to effective therapy. The identification of multiple mechanisms of tumor-induced immune suppression also provides a range of novel targets for new cancer therapies. Given the vital role that a host's immune response is known to play in cancer progression, therapies that target immune suppressive mechanisms have the potential to enhance anticancer immune responses thus leading to better immune surveillance and the limitation of tumor escape. In this review, mechanisms of tumor-associated immune suppression have been divided into four forms that we have designated as 1) Regulatory cells; 2) Cytokines/Chemokines; 3) T cell tolerance/exhaustion and 4) Metabolic. We discuss select mechanisms representing each of these forms of
\end{abstract}


immunosuppression that have been shown to aid tumors in evading host immune surveillance and overview therapeutic strategies that have been recently devised to "suppress these suppressors." 


\section{INTRODUCTION [Heading 1]}

Most conventional cancer therapies, such as radio- and chemo-therapies, are not tumor-specific and therefore a major drawback of these treatments is the undesirable effects on normal tissues. Although once controversial, it is now clear that our immune systems are capable of recognizing tumor cells and can play an important role in tumor control as well as tumor progression [1]. Indeed, T lymphocytes and antibodies that are specifically able to recognize tumor-associated antigens (TAA) are commonly found in cancer patients [2,3]. Other non-specific but activated immune effector cells, such as macrophages, natural killer (NK) and NKT cells may also be capable of attacking tumor cells and have also been found in patients with cancer [4]. The recognition of malignant cells by these immune system components has been termed "immune surveillance" [5,6]. Cancer progression occurs as a result of a failure in effective immune surveillance. There are now well-established immune-based therapies that have become standardof-care treatments for a variety of cancers, including the use of monoclonal antibodies (mAbs), immune adjuvants and vaccines against oncogenic viruses.

Immunotherapeutic approaches that utilize components of a host's immune system can be targeted to cancer cells and, given the nature of metastatic disease, are ideally suited for treatment of this disseminated disease state. Therefore, given the potential for tumor-specific targeting, the possibility of utilizing components of the immune system to control tumor progression is enticing for both clinicians and researchers. However, although the necessary machinery for an effective antitumor immune response may be present in tumor-bearing hosts, either naturally or induced through therapeutic manipulations, this is not enough since most cancers that have escaped immune surveillance still progress. This tumor immune escape occurs due to the selection of cancer cells resistant to immune attack, a process termed immunoediting. This is where immune recognition of malignant cells imposes a selective pressure on developing neoplasm's, resulting in the outgrowth of less immunogenic or more apoptosis-resistant escape variants $[5,6]$. The molecular alterations that occur in tumor cells that allow them to evade immune recognition have been reviewed elsewhere $[7,8]$. In this article we concentrate on tumor immune escape mechanisms facilitated by the induction of immune suppression, such as the production of soluble immunosuppressive factors produced by either tumor-infiltrating leukocytes (TILs) or by the tumor cells themselves; and/or the recruitment of suppressive or regulatory cells from the adaptive or innate arms of the immune system. The study of immune evasion mechanisms and 
the development of therapies targeting these pathways are complicated by the ever-evolving capacity of tumors to "adapt" and subvert antitumor immune responses through establishing their own unique microenvironment and immune signatures.

\section{Immunotherapy [Sub-heading 1]}

Immunotherapeutic strategies can be divided into two arms, either 1) active immunization, which stimulates hosts antitumor responses through such methods as vaccination or cytokine administration; or 2) passive immunization, whereby preformed tumor-specific T cells or antibodies are transferred into the host. Antibodies have been in clinical use for many years and have been redesigned and humanized for better safety and efficacy. These mAbs have been used to manipulate different pathways including, neutralization of immunosuppressive cytokines or inhibitory ligands/receptors, targeting suppressor cells, or the removal of suppressive elements produced by tumor cells. Examples of antibodies currently used for cancer therapy include Rituximab that targets CD20 and is used to treat B cell lymphoma, and Trastuzamab, which inhibits receptor signaling in HER-2-positive breast cancer (reviewed in more detail by [9]). Adoptive transfer approaches use in vitro or ex vivo expanded tumor-reactive T cells obtained from sources such as peripheral blood, lymph nodes or tumors that are then infused back into patients $[10,11]$. Recently, T cells that have been engineered to better recognize tumor antigens, or migrate to the sites of tumor, have been used to obtain greater therapeutic efficacy $[12,13]$. The effectiveness of treatments with adoptively transferred $\mathrm{T}$ cells may also be enhanced by combining with patient lymphodepletion and/or the administration of factors that support the survival of the transferred cells such as IL-2, and more recently IL-15 and IL-7. Significant progress has also been made in enhancing antitumor responses through such methods as immunization using tumor-associated antigens or administration of cytokines or other adjuvants (eg.CpG), which are designed to stimulate existing antitumor responses [14]. Since it has become evident that no single agent therapy will be sufficient to control established tumors, more effective cancer treatment strategies will require combination therapeutic approaches. These combinations could incorporate strategies designed to both augment specific antitumor immune responses and suppress the induction of immune suppressive pathways that limit these antitumor responses by limiting their generation or reducing their numbers/survival and/or function. 
Despite the promise of immunotherapeutic strategies and the numerous clinical trials that have utilized immune based therapies for the treatment of patients with cancer, the elicitation of consistent clinical responses has been disappointing. This is probably due to the induction of immune suppressive mechanisms that have evolved as a means to control the stimulation of "immunity to self", but can be opportunistically utilized or usurped by cancers to enhance their own survival and/or progression, particularly since many TAA are self-antigens. Therefore, both active and passive forms of cancer immunotherapy will probably be most effective when administered in combination with a reduction in tumor-induced immune suppression that permits effective and persistent antitumor responses. The number and redundancy of the antitumor regulatory mechanisms that have been identified, highlights the significant barriers that will need to be overcome to permit effective immunotherapy of cancer. However, given the vital role a host's immune system plays in whether cancer progression occurs; and the potential of immunotherapeutic strategies for fighting cancer, particularly metastatic disease, overcoming these barriers is an important pursuit for tumor immunologists. The elucidation of immunosuppressive networks and their components has also revealed potential targets, which if inhibited may be an effective strategy for the generation of more successful immunotherapies for cancer. We will discuss a number of tumor-associated mechanisms that result in immune suppression and review some of the methods scientists have developed to redress the balance towards efficacious antitumor responses.

For the purposes of this review we have classified these immunosuppressive mechanisms of action into four broad groups. 1) Regulatory cells: Tumors can recruit or activate negative regulatory immune cells, including myeloid derived suppressor cells (MDSC), regulatory T (Treg) cells, Th17 and natural killer T (NKT) cells that sometimes suppress antitumor immune responses. 2) Cytokines/Chemokines: The production of cytokines or chemokines by either tumor cells or other immune cells, may suppress effector cell responses by limiting their antitumor function or migration and skewing them towards a more pro-tumorigenic phenotype. 3) Effector cell Tolerance/Exhaustion: As well as inhibiting their activation, proliferation or migration, effector cells may become tolerant or their function "exhausted" through such mechanisms as inappropriate stimulation or chronic antigen exposure. 4) Metabolic: Effector cell function can also be affected metabolically by limiting their access to necessary substances required for proper cell function or proliferation. For select mechanisms within each of these 
groups, some techniques by which researchers have attempted to enhance antitumor responses by suppressing these immune suppressive mechanisms will be reviewed.

\section{[1] Regulatory Cells [Heading 2]}

Tumor-specific T lymphocytes have been identified in tumor-bearing hosts and their numbers can be successfully increased by immunotherapeutic processes such as vaccination. However, despite the presence of these tumor-specific cell types, cancers can continue to progress unabated. Accumulating evidence highlights the role of regulatory cells that can induce self tolerance, which is important because many tumor-associated antigens are self antigens. Other key components responsible for inhibiting an effective antitumor immune response are the immune suppressive myeloid cells, which are increased in numbers in tumor-bearing hosts. In this review we will focus on MDSC and NKT cells. Further regulatory cell types include the Th17 and Treg cells, which play a major role in the control of immunity to self-antigens and the prevention of autoimmunity. Th17 cells are characterized by their production of IL-17 and are involved in the pathogenesis of various autoimmune and allergic diseases, although their role in the tumor microenvironment has yet to be elucidated [15]. Because Treg cells have previously been extensively reviewed [16-18] we will not cover them here.

One way of reducing immunoregulatory cell types is by radio- or chemo-therapeutic depletion. Indeed, the lymphodepletion of cancer patients prior to $\mathrm{T}$ cell adoptive transfer has been shown to enhance the antitumor efficacy of transferred cells. However, this approach will significantly impact other cells of a patient's immune system including memory cells established to combat infections and therefore more specific therapies need to be developed.

\section{Myeloid-derived suppressor cells [Sub-heading 1]}

Progressive tumor growth is associated with an increase in a population of cells now known as myeloid-derived suppressor cells (MDSC). This is a heterogeneous population that in mice is identified by the co-expression of CD11b and Gr1 cell surface markers and includes immature precursors of DCs, macrophages, monocytes and granulocytes [19]. In numerous experimental models of cancer MDSC have been shown to accumulate at the site of tumor and peripherally in the blood, spleen, and bone marrow and to a lesser extent lymph nodes [20]. These cells are thought to be recruited from the bone marrow through the production of tumor-derived factors 
(TDF), which include vascular endothelial growth factor (VEGF), transforming growth factor (TGF)- $\beta$, IL-6, IL-10, colony-stimulating factor (CSF)-1 and granulocyte-macrophage colonystimulating factor (GM-CSF) [19]. The level of MDSC accumulation and the subtypes of cells that make up this heterogeneous MDSC population is dependent on the tumor burden and the profile of factors that the tumor and associated host cells are producing [21,22]. Although not as extensively studied in human cancer patients, MDSC are known to accumulate and have been identified in blood and at the site of tumor [23-25]. These cells are typically

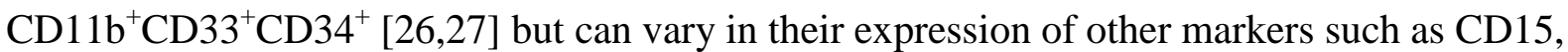
CD14 and HLA-DR [28,29], suggesting that, as in preclinical models, the induction of different balances of cellular subtypes within the MDSC population is dependent on the tumor type and the factors that it produces. In both preclinical mouse models and patients with cancer, there exists a correlation between increased MDSC numbers and the development of immune suppression [27]. Higher circulating levels of MDSC have also been correlated with advanced disease and a poorer prognosis, with surgical resection of tumors resulting in a decrease in peripheral blood MDSC [30], thus highlighting the link between MDSC, immune suppression and tumor progression.

As their name suggests, MDSC have the ability to suppress immune responses, both innate and adaptive, tumor-specific and non-specific. A number of diverse mechanisms have been identified by which MDSC can suppress antitumor immune responses (reviewed in detail by [22,31]), including production of arginase, nitric oxide synthase (NOS) and IL-10. IL-10 can indirectly suppress antitumor $\mathrm{T}$ cell responses by inhibiting the ability of antigen presenting cells (DCs and macrophages) to produce cytokines and express MHC and co-stimulatory molecules [32-34], which are required for appropriate T cell activation. Stimulation by IL-10 and TGF $\beta$ also induces MDSC to produce high levels of the immunoregulatory enzymes arginase I and NOS, which metabolize L-arginine to nitric oxide (NO) and hydroxide (See Metabolic section). These reactive oxygen species (ROS) can also directly inhibit $\mathrm{T}$ cell function as well as induce $\mathrm{T}$ cell apoptosis [35-37]. Therefore, pharmacological inhibition of NOS and arginase-mediated suppressive pathways represent promising targets for overcoming MDSC-induced immunosuppression and are currently being explored [38]. MDSC can also influence the production of tumor-derived indoleamine-2,2-dioxygenase (IDO), which catabolizes tryptophan, an essential amino acid for T cell differentiation (See Metabolic section). 


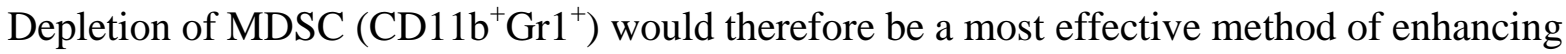
antitumor immune responses however; their heterogeneity and defining surface markers make it difficult to specifically target this cell population. It has been demonstrated in mouse tumor transplant models that depletion of myeloid cells by anti-Gr1 mAb can limit tumor growth [39]. The efficacy of depleting MDSC to enhance other immunotherapeutic strategies has also been demonstrated in a number of preclinical models. For example when anti-Gr1 mAb was combined with anti-CTLA4 there was a significant synergistic therapeutic effect compared to treatment with the single antibodies [40]. Despite apparent anti-Gr1-mediated enhancement of antitumor effects in preclinical models of cancer, a major drawback of using anti-Gr1 depletion antibodies in the long-term is that Gr-1 is expressed on a range of cell types including neutrophils, granulocytes and memory $\mathrm{CD} 8^{+} \mathrm{T}$ cells; depletion of which would severely compromise a host's ability to mount an effective immune response to other challenges. Similar problems would exist if targeting MDSC in human patients using the current identifying cell surface markers.

Therefore, therapeutic strategies aimed at reducing the immunosuppressive effects of MDSC may require the design of therapies that target the induced immune suppressive pathways rather than directly eliminating the cells responsible.

In a spontaneous model of mammary carcinoma, the pro-tumorigenic behavior of MDSC was found to be diminished when the expression of interferon regulatory factor-8 (IRF-8) was enhanced [41]. This inhibition in MDSC function may have been due, at least in part, to a reversion in their cytokine/chemokine expression profile to one that more closely resembled the production profile of $\mathrm{CD} 1 \mathrm{~b}^{+} \mathrm{Gr}^{+}$cells from non-tumor-bearing mice. These studies also revealed that tumor-induced MDSC have elevated expression levels of CCL2 (MCP-1) and MIP$1 \alpha$ and diminished amounts of CCL5 (RANTES) compared to similar cells from non-tumorbearing mice. IRF-8 is a key myeloid-associated transcription factor that is essential for normal myelopoiesis and when overexpressed was also shown to reduce the number of tumor-induced MDSC that accumulated in the periphery [40]. The tumor-induced reduction in IRF-8 expression in MDSC may be a novel target for therapeutic manipulation as a means of reducing MDSC numbers and immune suppression. In mice, the in vivo inactivation of genes that govern MDSC accumulation, such as STAT-3 and STAT-6 have also been shown to restore T cell activation and promote tumor regression and/or resistance to metastatic disease [42-44]. 
MDSC are considered to have aberrant myeloid cell differentiation and since the balance of immature and mature myeloid cells in vivo can have a significant effect on both naturally occurring and therapy induced antitumor T cell responses; another method that has been investigated as a way to reduce MDSC suppression is to drive their maturation or differentiation. This has been achieved with limited success in preclinical mouse models through the administration of all-trans-retinoic acid (ATRA), interferon (IFN)- $\gamma$ or vitamin D3 [45-47]. Treatment of renal cell carcinoma patients with ATRA was also found to enhance their immune responses and myeloid cell differentiation [48].

Some commonly used cytotoxic agents in the treatment of cancer have also exhibited a capacity to deplete MDSC in experimental cancer models. Gemcitabine and sunitinib have been shown to inhibit MDSC-mediated immune suppression and enhance other immune-based cancer therapies [49-52]. A recent article suggests that 5-Fluorouracil (5FU) is even more effective at directly killing MDSC than gemcitabine [53]. These cytotoxic agents appeared to selectively reduce the number of MDSC found in the tumor and spleen, with no significant reductions in other types of immune cells. This preclinical data has been mirrored in humans, where treatment of renal cell carcinoma patients with sunitinib was shown to reduce MDSC accumulation [54]. The use of gemcitabine as an immune adjuvant is currently undergoing clinical trial [55]. Therefore, data supports a role for anticancer agents beyond their direct cytotoxicity of tumor cells that could also enhance immune responses through the elimination of MDSC. This role should be considered when designing future treatment strategies and may prove particularly useful when combined with immunotherapies aimed at stimulating antitumor immune responses.

\section{NKT cells [Sub-heading 1]}

CD1d-restricted natural killer T (NKT) cells have emerged, at least in mice, as an important regulator of inflammatory responses in cancer [56,57]. Although these cells express a T-cellreceptor (TCR), they are often classified as an innate lymphocyte population based on their rapid response to non-MHC-restricted recognition of lipid/glycolipid antigens in association with the CD1d presentation molecule. At least two populations of CD1d-restricted NKT cells are associated with tumor immunity [58,59]. The most extensively studied population, sometimes defined as type I NKT cells or iNKT cells, are generally thought to promote or execute antitumor immunity and in mice can be divided into functionally distinct subsets based on NK1.1 and CD4 
expression [57]. A homologous population of iNKT cells also exists in humans, identified by the Va24/V $\beta 11$ TCR. Type I NKT cells can positively modulate dendritic cell (DC) and B cell function and it is clear that agonist CD1d ligands are powerful adjuvants for driving both cellmediated and antibody responses in mice [60]. These cells can enhance antitumor responses through the production of IFN- $\gamma$ which activates and matures DC to make IL-12, which in turn activates $\mathrm{NK}$ and $\mathrm{CD}^{+} \mathrm{T}$ cells [61]. In contrast, type II NKT cells express a more diverse TCR repertoire that recognize lipids presented by CD1d and have been identified in both humans and mice. Less is known as to their significance and role in regulating tumor immune surveillance, although accumulating evidence in preclinical tumor models suggests that these cells have a regulatory, immune suppressive phenotype [62-66]. Although their immune suppressive capacity remains to be directly verified, since a knock-out mouse does not yet exist, the mechanism of suppression appears to involve IL-13 and the stimulation of myeloid TGF- $\beta$ [67-69], but it is very likely other presently unrecognized immunosuppressive mechanisms also exist. Therefore, strategies that support an antitumor type I NKT response and limit the inhibitory type II NKT responses may not only have direct antitumor effects but also have the capacity to support the adaptive (tumor-specific) immune responses.

\section{[2] Cytokine and Chemokines [Heading 2]}

Recombinant cytokine proteins have been used to enhance a range of immune responses and have demonstrated great promise in reducing tumor-induced immune suppression (eg. IL-2, IL-12, IL15/7, GM-CSF and interferons) (Reviewed in [70]). However, we will concentrate on discussing strategies for suppressing the immunoinhibitory cytokines which can be produced by tumor cells, tumor-infiltrating immune cells and other stromal cells within the tumor microenvironment. They not only have the potential to effect immune responses at the site of tumor but also systemically, which can lead to the overall reduced immune competency of cancer patients. Chemokines are also attractive targets for immunotherapy due to their influences on immune cell migration and function (reviewed in [71]). In their function as chemotactic cytokines they can be targeted to reduce trafficking of regulatory cells or increase migration of effector cells to sites of tumor.

\section{TGF- $\boldsymbol{\beta}$ [Sub-heading 1]}


Transforming growth factor (TGF)- $\beta$ is produced by tumor cells and tumor-infiltrating immune cells within the tumor microenvironment and its role in immune suppression includes the inhibition of T cell proliferation, cytokine production and cytotoxicity [72,73]. As well as contributing to the remodeling of the tumor microenvironment (angiogenesis), TGF- $\beta$ recruits the Treg and MDSC immune suppressive cell types and can enhance Treg survival and function by the induction of FOXP3 [74]. Under some conditions TGF- $\beta$ can also inhibit antigen presenting cell (APC) function by suppressing cell maturation, inhibiting IFN- $\gamma$ production and inducing MHC class II down-regulation [75,76]. Due to its role in these multiple immune suppressive pathways, TGF- $\beta$ is therefore an attractive therapeutic target. However, care is needed since TGF- $\beta$ can act as both a tumor suppressor and promoter [77]. Therefore, successful treatments that include TGF- $\beta$ antagonism will probably require monitoring of a tumors immune signature for when TGF- $\beta$ switches from being a tumor suppressor to actually promoting tumor growth. A number of therapeutic approaches have been developed, including neutralizing mAbs (eg. Infliximab, Lerdelimumab, Metelimumab \& GC-1008) or small molecule inhibitors of TGF- $\beta$ signaling. In a range of solid tumor preclinical models, neutralizing TGF- $\beta$ mAbs alone were found not to have an antitumor effect. However, when anti-TGF- $\beta$ treatment was combined with other vaccine based immunotherapies there was a significant improvement in antitumor efficacy and an enhancement in $\mathrm{CD}^{+} \mathrm{T}$ cell and NK cell-mediated immune responses [78-80]. These large molecule therapies therefore appear promising as an adjuvant to improve other tumorspecific immunotherapies. Also only in preclinical models, small molecule TGF- $\beta$ receptor I kinase inhibitors have been shown to block TGF- $\beta$ signaling in both immune and tumor cells as well as extend the survival of tumor-bearing animals [81]. Interestingly, this may not correlate with an alteration in tumor cell proliferation or apoptosis, but rather an increased immune cell infiltrate into the tumor [82], which could be a rationale for the use of TGF- $\beta$ antagonism therapy in combination with tumor-specific immunotherapeutic approaches.

The only TGF- $\beta$ targeted treatment strategy that has so far been translated into a clinical trial for the treatment of solid tumors, is the use of antisense technology that targets TGF- $\beta$ isoform mRNA for sequence specific degradation. These antisense oligodeoxynucleotides are commonly used to study gene function; however, they have also been designed for therapy of high grade gliomas. AP 12009 (trabedersen), which targets mRNA encoding TGF- $\beta 2$ has been evaluated for 
dose and toxicity in Phase I and II clinical trials and is currently employed in Phase III trials for the treatment of malignant gliomas $[83,84]$. A TGF- $\beta 2$ antisense gene has also been used to modify an allogeneic tumor vaccine (Belagenpumatucel-L) for use in a Phase II trial for the treatment of advanced non-small cell lung cancer [85]. Overall, this form of therapy was reported to be well tolerated and significantly inhibited disease progression. Inhibition of TGF- $\beta$ activity therefore appears a viable therapeutic option, particularly as an adjuvant for other immunotherapeutic strategies.

\section{IL-10 [Sub-heading 1]}

Along with TGF- $\beta$, interleukin-10 (IL-10) is of considerable interest as a therapeutic target due to its defined roles in tumor-induced immune suppression. IL-10 production is not only a mechanism by which MDSC induce immunosuppression (see above) it is also produced by tumor-associated macrophages (TAMs) and other TILs, as well as by the tumor cells. Tumorderived IL-10 has been shown to interfere with the stimulation of antitumor responses by inhibiting the expression of the CD40 co-stimulatory molecule on APC. Tr1 cells also induce T cell anergy and immune suppression by the production of high levels of IL-10 and TGF- $\beta$. However, IL-10 has been reported to have pleiotropic activities and its role in immune suppression and tumor progression is therefore controversial [86]. Although, antibodies against IL-10 or its receptors have been used in the treatment of other inflammatory diseases, their application in the treatment of cancer has not, as yet, been translated to the clinic, but is expected in the near future.

\section{VEGF [Sub-heading 1]}

Vascular endothelial growth factor (VEGF) is well known as a major player in normal and tumorassociated angiogenesis and as such has been targeted with anti-VEGF antibodies (Bevacizumab) with the expectation of inhibiting cancer growth by reducing blood flow to the tumor [87]. There is however accumulating evidence for a role for VEGF in tumor-induced immune suppression [88]. VEGF has been associated with the recruitment of MDSC and macrophages to the site of tumor along with an inhibition in myeloid cell maturation, including DCs, which limits their function as APC. The use of VEGF neutralizing antibody, at least in preclinical models, has been associated with increased DC priming activity [89] and effector cell numbers compared to Treg 
cells and improved immunotherapy efficacy [90,91]. A decrease in the accumulation of immature progenitor cells and an increase in peripheral DCs have also been noted in cancer patients treated with bevacizumab [92]. Given the effect of anti-VEGF therapy in improving immune responses, combining this form of treatment with other immunotherapeutic strategies may be advantageous. Indeed, a clinical trial combining vaccination (APC8015: peptide pulsed DCs) with bevacizumab was found to induce an antitumor immune response as well as modulate prostate specific antigen levels in patients with biochemically recurrent prostate cancer [93].

\section{CCL2 [Sub-heading 1]}

CCL2 or monocyte chemoattractant protein-1 (MCP-1) is a chemokine first identified as a mediator of monocyte migration. It has since been shown to influence the migration of many other cell types including lymphocytes (eg. Treg and NKs) and endothelial cells [94,95]. CCL2 is produced by many tumor cell types and has both direct and indirect immune suppressive effects, including the direct inhibition of $\mathrm{CD}^{+} \mathrm{T}$ cell functions $[96,97]$. Factors, such as cytokines and chemokines, released by tumor cells or other cells within the tumor microenvironment mediate the influx of immune cells, which can have pro-tumorigenic and immunosuppressive effects. A number of studies have demonstrated a correlation of CCL2 production within the tumor with the accumulation of tumor-associated macrophages (TAM) [98] and Treg [99]. TAM play a significant role in promoting tumor growth through the promotion of angiogenesis and inhibition of immune responses [100]. In a cancer setting, CCL2 may therefore be considered a protumorigenic and immunoregulatory chemokine, thus a target for therapeutic manipulation. In a preclinical mouse model of prostate cancer, treatment with mAbs that block CCL2 activity have been shown to have a limited effect at reducing tumor growth and could limit the numbers of TAM [101,102]. Another recent article demonstrated no reduction in tumor-infiltrating monocytes but rather a significant decrease in the numbers of Treg. The therapeutic effect on NSCLC and mesothelioma tumor growth and enhanced antitumor responses was seen when combined with other immunotherapeutic strategies [103]. Therefore, CCL2 blockade appears a potential adjuvant for cancer therapy but its mechanism of action may be multifactorial and tumor type or timing dependent.

\section{[3] T cell exhaustion [Heading 2]}


Mechanisms have been identified whereby tumor cells actively attack or inhibit immune cells and include cross-linking of the TRAIL or CD95 (Fas) death receptors expressed on T cells by tumor expression of the TRAIL or CD95 ligands (FasL) [104]. Cytotoxic T lymphocytes (CTL) are a major effector cell type responsible for attacking tumor cells and require specific conditions to become fully activated. These conditions include the presentation of specific antigens by mature APC that co-express co-stimulatory molecules (eg. CD80/B7-1 \& CD86/B7-2) and an appropriate cytokine milieu. Chronic antigen exposure or the inappropriate or insufficient expression of co-stimulatory molecules on APC can induce T cell tolerance or anergy rather than antitumor immunity [105]. Tumor cells themselves are not professional APC and usually express low levels of co-stimulatory molecules and are therefore poor activators of antitumor T cell responses. Tumor cells may also be responsible for the downregulation of co-stimulatory molecules on the professional APC, which can lead to death or anergy of tumor-specific T cells. To overcome this tumor-induced unresponsiveness, viral vectors have been used to deliver costimulatory genes to tumor cells with the expectation of making them better able to stimulate antitumor responses to the antigens that they present. In preclinical models, these vaccines were successful at reducing tumor burden and increasing tumor specific T cell numbers [106]. This form of cancer vaccine has been used to immunize cancer patients with a range of solid tumors, but although increases in the frequency of peripheral tumor specific T cells were detected, actual tumor regressions were rare [107,108]. DCs, which are the major professional APC, can be prevented from becoming fully mature APC through interactions with tumor cells and thus become unable to fully activate $\mathrm{T}$ cells for effective antitumor function. Tumors can also induce defective T cell signaling pathways through the downregulation of the common cytokine receptor $\gamma$ chain and the pro-survival members of the Bcl-2 family $[109,110]$. As a result, the balance between stimulation of immunogenic rather than tolerogenic immune responses in the tumor microenvironment is skewed towards an ineffective immune response.

\section{CTLA-4 [Sub-heading-1]}

Cytotoxic T lymphocyte antigen-4 (CTLA-4, also called CD152) is a negative immunoregulatory receptor expressed on Treg and activated T cells. CTLA-4 competes with higher affinity for the ligands of the co-stimulatory molecule CD28. These ligands are expressed on APC or tumor cells with signaling through the inhibitory CTLA-4 molecule on T cells inhibiting their effector 
functions. The balance between expression of the co-stimulatory molecule CD28 and inhibitory signals mediated by CTLA-4 is a critical control point in determining whether a $\mathrm{T}$ cell becomes fully activated or is tolerized [111]. Activation of the IDO immunoregulatory enzyme (see Metabolic section) has also been shown to be a downstream effect of the CTLA-4 signaling pathway [112]. Because of the role CTLA-4 plays in undermining antitumor T cell responses the use of CTLA-4 blockade in combination with a range of cancer immunotherapies has been investigated in preclinical models and found to restore antitumor T cell responsiveness [113,114]. Based on these encouraging results a number of anti-CTLA-4 humanized mAbs have been developed that aim to enhance antitumor $\mathrm{T}$ cell responses by blocking the negative signaling and resulting reduction in $\mathrm{T}$ cell function that occurs following CTLA-4 engagement. A number of clinical trials, particularly in the treatment of melanoma and other solid tumors, have been undertaken that have enabled the study of combining CTLA-4 interference with other cancer immunotherapies [115]. For example, tremelimumab and ipilimumab are anti-CTLA-4 mAbs that are currently undergoing phase II and III clinical trials for the treatment of a range of cancers. The results of published clinical trials have demonstrated a clear role for CTLA-4 in maintaining a state of peripheral tolerance in humans with cancer and some associated objective cancer regressions $[116,117]$. However, as may be expected there was a significant incidence of autoimmunity induction, which when treated with corticosteroids did not seem to abrogate the clinical benefits [118]. These results support further clinical trials and investigations for the use of CTLA-4 blockade in cancer immunotherapy.

\section{PD-L1 [Sub-heading 1]}

The programmed death receptor ligand 1 (PD-L1; also called B7-H1, CD274) can be expressed on the surface of tumor cells and induce apoptosis of T cells [119]. In many human and preclinical models of cancer, PD-L1 is overexpressed by tumor cells compared to normal tissues, reportedly due to a loss of the PTEN tumor suppressor gene. This high PD-L1 expression on tumor cells has been correlated with decreased cancer patient survival. Tumor cells may therefore inhibit $\mathrm{T}$ cell function through direct interactions with $\mathrm{T}$ cells that express the PD-L1 cognate receptor PD-1 (CD279), resulting in decreased T cell proliferation and cytokine production. Analysis of PD-L1 expression on DCs from cancer patients has demonstrated a higher ratio of inhibitory PD-L1 to co-stimulatory molecule expression. Tumor-specific $\mathrm{CD}^{+} \mathrm{T}$ cells have also 
been shown to have upregulated PD-1 expression in patients with advanced melanoma [120] or ovarian cancer [121]. Tumor-induced dysfunction in T cells from advanced melanoma patients could also be attenuated by ex vivo PD-1/PD-L1 blockade [122]. This data supports the hypothesis that the tolerogenic state that exists within a tumor is due, at least in part; to tumor cell or APC induction of T cell immune tolerance through PD-L1 / PD-1 interactions [123]. Therefore, strategies that block the PD-L1/PD-1 pathway have been developed, such as anti-PDL1 or PD-1 antibodies or PD-1 decoy receptors. In preclinical models, PD-L1/PD-1 blockade has elicited enhanced antitumor T cell immunity [124] and has also been successfully combined with other immunotherapies to enhance their efficacy [125]. A humanized antibody (MDX-1106) that targets PD-1 has demonstrated promising results in phase I clinical trial [126] and warrants further investigation, particularly as a combination therapy.

\section{[4] Metabolic [Heading 2]}

Compared to many host tissues, tumors have a high metabolic activity but are severely constrained by a restricted access to nutrients. It has become evident that tumor cells or their immune infiltrating cells have profound influences on the metabolism of nutrients, such as amino acids, arachidonic acid and adenosine, which are essential for proper cell function. The control of amino acid metabolism has been shown to be a particularly important strategy by which higher organisms can limit the unwanted expansion of actively proliferating cells, including $\mathrm{T}$ cells [127]. Study of these metabolic pathways and their possible toxic metabolites, within the tumor microenvironment have revealed targets with therapeutic potential.

\section{Arginase/Nitric-oxide Synthase [Sub-heading 1]}

L-arginine is an essential amino acid that $\mathrm{T}$ cells require for proper function and which when not available leads to a downregulation of the $\mathrm{T}$ cell receptor and an inhibition in antigen-specific $\mathrm{T}$ cell responses. The two major enzymes responsible for the catabolism of arginine are arginase I and nitric-oxide synthase (NOS), which when expressed at high levels within the tumor microenvironment leads to a deficiency in the availability of arginine and a decrease in immune cell function $[128,129]$. The byproducts of this process, such as ornithine, have also been shown to inhibit T-cell function [37]. The L-arginine analogue N-hydroxy-nor-L-arginine, also known as Nor-NOHA has been used to inhibit arginase activity and when used as an anticancer therapy 
against Lewis lung carcinoma cells, successfully inhibited primary tumor growth by an myeloid cell mediated mechanism [130].

As mentioned previously, a major source of arginase I is the MDSC that accumulate at the tumor site [22] and unlike macrophages MDSCs can upregulate both arginase and inducible NOS simultaneously [36]. Since inhibition or depletion of tumor-induced MDSC is problematic (see above), a reduction in their immunosuppressive mediators may be a better therapeutic option. The importance of inhibiting both NOS (eg. By NG-monomethyl-arginine (1-NMMA)) and arginase activity to restore $\mathrm{T}$ cell expansion and cytolytic function in MDSC-mediated immunosuppression, was demonstrated by using a combination of inhibitors that targeted each individual pathway [131]; or by using a single nitroaspirin (NCX-4016) agent that was capable of inhibiting both the arginase and NOS pathways, but was ineffective when NOS or arginase inhibition was used alone [38]. This nitroaspirin was also found to increase the number of tumorspecific CTL, and the survival of tumor-bearing animals, when combined with a tumor vaccine. Since it appears that blocking both arginase and NOS-mediated immune suppressive pathways may be required for effective therapy the most promising therapeutics to inhibit arginase/NOSmediated immunosuppression would be dual inhibitors such as NCX-4016, which is currently in clinical trials for other indications.

\section{Adenosine [Sub-heading 1]}

Adenosine is a purine nucleoside that is often present at high concentrations within a tumor where it is synthesized from the catabolism of adenine nucleotides (ATP, ADP and AMP) by the enzymatic actions of the CD39 and CD73 extracellular ectonucleotidases (reviewed in [132]). Extracellular adenosine has both immunosuppressive and pro-angiogenic effects and can be produced by tumor cells as well as by Treg [133]. Adenosine receptors $\left(A_{1}, A_{2 a}, A_{2 b}\right.$ and $\left.A_{3}\right)$ are expressed by a number of effector immune cell types and also by tumor cells, and when bound leads to inhibition of immune responses and enhanced tumor growth [134,135]. Therefore, approaches that limit the accumulation of extracellular adenosine may be another means of enhancing antitumor immune responses. Indeed, there are a number of inhibitory small molecular weight molecules and adenosine receptor antagonists that are already in use for the treatment of other diseases and could easily be trialed as a cancer therapeutic for the inhibition of antitumor immune suppression. It has also been demonstrated in preclinical models of breast cancer that 
anti-CD73 mAb therapy can significantly retard primary tumor growth and the development of metastasis as well as enhance adaptive antitumor immunity [136].

\section{IDO [Sub-heading 1]}

The indoleamine-2,2-dioxygenase (IDO) enzyme can be expressed by tumor cells and associated stromal cells and is responsible for catalyzing the degradation of the essential amino acid tryptophan to N-formyl-kynurenine. Many tumors and tumor draining lymph nodes have been shown to have elevated levels of IDO expression [137] and in patients elevated levels of IDOgenerated metabolites have been associated with a number of malignancies $[138,139]$. Although IDO may be expressed in a variety of tissues, it is particularly and specifically induced in cells of the immune system, such as DCs and macrophages, by inflammatory cytokines such as IFN- $\gamma$, which is a particularly potent and well characterized inducer of IDO activity. The significant effect IDO can have on suppressing immune responses is highlighted by its ability to negate the maternal T cell responses against an allogeneic fetus [140]. This immunosuppressive enzyme can induce immune tolerance by either depleting the localized area of tryptophan or by the accumulation of toxic catabolites. IDO has also been implicated in CTLA-4 induced immune tolerance mediated through reverse B7 signaling with APC [141]. Alternatively, and possibly more relevantly for IDO driven immune suppression, is the production of IDO by immune cells that travel from the tumor stroma to the draining lymph nodes, which are the primary sites for immune activation. The effects of this immunosuppressive pathway is supported by data indicating that host, rather than tumor-derived IDO, enhanced tumor growth and that the host cells responsible were identified as a DC subset with plasmacytoid morphology [142]. The resulting depletion of tryptophan and accumulation of its metabolic products, inhibits immune responses by blocking $\mathrm{T}$ cell activation and inducing $\mathrm{T}$ cell apoptosis as well as driving cells towards a Treg phenotype [143].

Given the substantial evidence for IDO- mediated immune tolerance in cancer and other diseases, there has been a recent explosion in the design of IDO inhibitors and studies that target IDO for anticancer therapy. This is due in part to its well defined biochemistry and because it is only one of two enzymes that catalyze the same reaction; the other, IDO2, having a more restricted expression and substrate specificity, which may limit "off-target" effects. Promising small molecule inhibitors such as the widely used structural analog, 1-Methyl tryptophan (1MT) have 
been shown to block IDO activity and reduce immune suppression (reviewed in [138,144]). In preclinical cancer models, IDO inhibition either by small inhibitory molecules or IDO-specific siRNAs, has also demonstrated a capacity to significantly enhance the efficacy of traditional chemotherapeutic drugs and immunotherapies [138,145]. Several natural products (eg. brassinin, exiguamine) have also been identified as IDO inhibitors and along with a new wave of inhibitors that have undergone medicinal chemistry manipulation there are numerous IDO inhibitors available for clinical trial testing. The IDO inhibitor, d-1-methyl-tryptophan (d-1-MT), is being evaluated in a number of phase I trials in the United States in patients with advanced solid tumors. Based on the evidence for considerable IDO involvement in human cancers and tumorinduced immune suppression, IDO inhibition holds a promise for significant suppression of the IDO suppressive pathway and enhancement of antitumor immune responses. Importantly, enhanced antitumor activity has been demonstrated when IDO inhibitors have been used in combination with other cytotoxic agents or immune based therapies, compared to the individual agents alone.

\section{COX2/PGE 2 [Sub-heading 1]}

Prostaglandin E2 $\left(\mathrm{PGE}_{2}\right)$ is well known for its pro-tumorigenic capacity and ability to promote angiogenesis and tumor cell migration [146]. Prostaglandins and thromboxanes also have immunoinhibitory properties and are produced from the degradation of arachidonic acid by the inducible form of the cyclooxygenase enzyme (COX2), which is overexpressed in a variety of tumor types $[147,148]$. The immunosuppressive effects of $\mathrm{PGE}_{2}$ include inhibition of DC maturation, T cell proliferation and function, as well as the downregulation of pro-inflammatory chemokines and type 1 cytokines $[149,150]$. In studies of some cancer patients, negative effects on DC and T cell function have been correlated with tumor expression of COX2 and $\mathrm{PGE}_{2}$ as well as an increase in Treg mediated suppression $[151,152]$. Tumor cell production of $\mathrm{PGE}_{2}$ has also been shown to upregulate the expression of IDO and arginase by myeloid cells. Inhibition of $\mathrm{PGE}_{2}$ may therefore be an alternative downstream target for reducing the immunosuppressive effects of IDO and arginase (see above).

The strong effects of $\mathrm{PGE}_{2}$ and $\mathrm{COX} 2$ expression on tumor promotion and immune suppression make their inhibition a desirable option for incorporation in cancer treatment strategies. The use of COX2 inhibitors in preclinical models has resulted in significant reductions in tumor burdens 
and prolonged survival rates. The importance of COX2 in antitumor immune inhibition was demonstrated by an observed increase in tumor-infiltrating lymphocytes as well as IL-12 and IFN- $\gamma$ production following COX2 inhibition therapy [153]. COX2 inhibition has also been shown to enhance the efficacy of other immunotherapeutic strategies [154,155], which supports their potential for use in combination therapies. Selective COX2 inhibitors (eg. Celecoxib and rofecoxib) are already available for human use and have undergone clinical trials where they have been combined with chemotherapies. There appears to be a clinical benefit to patients on combination therapies compared to chemotherapeutics alone [156,157]. Therefore, overall results support the rationale design and trial of treatment strategies that combine the use of COX2 inhibitors and other immunotherapies, such as antitumor vaccines, for the treatment of cancer. Although given the recent reported risks of the current drugs, the development of less toxic inhibitors of the COX pathway or alternative targeting of the prostaglandin receptors will probably be undertaken.

\section{CONCLUSIONS [Heading 1]}

It has become clear that successful cancer treatments will probably require the administration of multiple therapies that effectively target different pro-tumorigenic pathways and disrupt the immunosuppressive networks. The treatment of cancer patients by restoration of effective antitumor immune responses may require approaches aimed at protecting antitumor immune cells from the effects of regulatory cells such as MDSC or the cytokines/chemokines that they produce; and/or prolonging the survival and function of effector cells by inhibiting negative stimulation and metabolic constraints. Different immunosuppressive mechanisms may be elicited dependent on the tumor type and may change with tumor progression and alterations in the tumor microenvironment. Therefore, tailoring the immunotherapeutic strategy and the timing of its administration will require the monitoring of the occurrence of immune suppressive mechanisms. Defining the molecular and functional profile of the tumor and its associated immune cells will be key to personalizing the selection of treatments, including immunotherapies that can be combined to form an overall strategy for limiting cancer progression. As our understanding of host-tumor interactions increases and our technical ability to monitor disease progression biomarkers expands, tailoring individualized treatment strategies will become a real therapeutic option for the treatment of cancer patients. 


\section{Key unanswered questions [Heading 2]}

- Continued mapping of tumor escape and immune suppressive networks will inform the design of more potent therapeutic strategies.

- Investigation of combination approaches that incorporate methods that reduce tumor burden, augment antitumor responses and inhibit the regulatory pathways that induce immune tolerance, will lead to more effective treatments for cancer patients.

- Developing methods that permit monitoring of the status of the cancer and an individuals immune system will allow tailoring of treatments and their timing, to target tumor escape pathways as they develop so that they have the highest chance of success at eliminating or reducing tumor progression and limit the need for "trial and error" treatment regimes.

- Understanding the molecular links between genetic mutations and epigenetics in tumors and the tumor immunosuppressive microenvironment that results.

\section{ACKNOWLEDGEMENTS [Heading 1]}

The authors wish to thank their funding partners who include the National Breast Cancer

Foundation, Cancer Council of Victoria, The Victorian Breast Cancer Research Consortium, The Susan G. Komen Breast Cancer Foundation, and the National Health and Medical Research Council of Australia. 


\section{REFERENCES [Heading 1]}

1. Stewart, T. J., Greeneltch, K. M., Lutsiak, M. E., \& Abrams, S. I. (2007). Immunological responses can have both pro- and antitumour effects: Implications for immunotherapy. Expert Rev Mol Med, 9(4), 1-20, doi:S1462399407000233 [pii]

$10.1017 /$ S1462399407000233.

2. Hamai, A., Benlalam, H., Meslin, F., Hasmim, M., Carre, T., Akalay, I., et al. Immune surveillance of human cancer: If the cytotoxic t-lymphocytes play the music, does the tumoral system call the tune? Tissue Antigens, 75(1), 1-8, doi:TAN1401 [pii]

10.1111/j.1399-0039.2009.01401.x.

3. Knutson, K. L., \& Disis, M. L. (2005). Tumor antigen-specific t helper cells in cancer immunity and immunotherapy. Cancer Immunol Immunother, 54(8), 721-728.

4. Bindea, G., Mlecnik, B., Fridman, W. H., Pages, F., \& Galon, J. Natural immunity to cancer in humans. Curr Opin Immunol, 22(2), 215-222, doi:S0952-7915(10)00038-5 [pii]

10.1016/j.coi.2010.02.006.

5. Dunn, G. P., Old, L. J., \& Schreiber, R. D. (2004). The immunobiology of cancer immunosurveillance and immunoediting. Immunity, 21(2), 137-148.

6. Swann, J. B., \& Smyth, M. J. (2007). Immune surveillance of tumors. J Clin Invest, 117(5), 1137-1146, doi:10.1172/JCI31405.

7. Ferrone, S., \& Whiteside, T. L. (2007). Tumor microenvironment and immune escape. Surg Oncol Clin N Am, 16(4), 755-774, viii, doi:S1055-3207(07)00098-1 [pii]

10.1016/j.soc.2007.08.004.

8. Stewart, T. J., \& Abrams, S. I. (2008). How tumours escape mass destruction. Oncogene, 27(45), 5894-5903, doi:onc2008268 [pii]

10.1038/onc.2008.268.

9. Weiner, L. M., Surana, R., \& Wang, S. Monoclonal antibodies: Versatile platforms for cancer immunotherapy. Nat Rev Immunol, 10(5), 317-327, doi:nri2744 [pii]

10.1038/nri2744.

10. Kapp, M., Rasche, L., Einsele, H., \& Grigoleit, G. U. (2009). Cellular therapy to control tumor progression. Curr Opin Hematol, 16(6), 437-443, doi:10.1097/MOH.0b013e32832f57d4.

11. Rosenberg, S. A., \& Dudley, M. E. (2009). Adoptive cell therapy for the treatment of patients with metastatic melanoma. Curr Opin Immunol, 21(2), 233-240, doi:S09527915(09)00025-9 [pii]

10.1016/j.coi.2009.03.002.

12. Huye, L. E., \& Dotti, G. Designing t cells for cancer immunotherapy. Discov Med, 9(47), 297-303.

13. Westwood, J. A., \& Kershaw, M. H. Genetic redirection of t cells for cancer therapy. $J$ Leukoc Biol, 87(5), 791-803, doi:jlb.1209824 [pii]

10.1189/jlb.1209824.

14. Spagnoli, G. C., Ebrahimi, M., Iezzi, G., Mengus, C., \& Zajac, P. Contemporary immunotherapy of solid tumors: From tumor-associated antigens to combination treatments. Curr Opin Drug Discov Devel, 13(2), 184-192.

15. Romagnani, S., Maggi, E., Liotta, F., Cosmi, L., \& Annunziato, F. (2009). Properties and origin of human th17 cells. Mol Immunol, 47(1), 3-7, doi:S0161-5890(08)00811-0 [pii]

10.1016/j.molimm.2008.12.019. 
16. Mougiakakos, D., Choudhury, A., Lladser, A., Kiessling, R., \& Johansson, C. C. Regulatory t cells in cancer. Adv Cancer Res, 107, 57-117, doi:S0065-230X(10)07003-X [pii]

10.1016/S0065-230X(10)07003-X.

17. Nishikawa, H., \& Sakaguchi, S. Regulatory t cells in tumor immunity. Int J Cancer, 127(4), 759-767, doi:10.1002/ijc.25429.

18. Teng, M. W., Ritchie, D. S., Neeson, P., \& Smyth, M. J. Biology and clinical observations of regulatory t cells in cancer immunology. Curr Top Microbiol Immunol, doi:10.1007/82_2010_50.

19. Serafini, P., Borrello, I., \& Bronte, V. (2006). Myeloid suppressor cells in cancer: Recruitment, phenotype, properties, and mechanisms of immune suppression. Semin Cancer Biol, 16(1), 53-65.

20. Allavena, P., Sica, A., Garlanda, C., \& Mantovani, A. (2008). The yin-yang of tumorassociated macrophages in neoplastic progression and immune surveillance. Immunol Rev, 222, 155-161, doi:IMR607 [pii]

10.1111/j.1600-065X.2008.00607.x.

21. Gabrilovich, D. I., \& Nagaraj, S. (2009). Myeloid-derived suppressor cells as regulators of the immune system. Nat Rev Immunol, 9(3), 162-174, doi:nri2506 [pii]

$10.1038 /$ nri2506.

22. Marigo, I., Dolcetti, L., Serafini, P., Zanovello, P., \& Bronte, V. (2008). Tumor-induced tolerance and immune suppression by myeloid derived suppressor cells. Immunol Rev, 222, 162-179, doi:IMR602 [pii]

10.1111/j.1600-065X.2008.00602.x.

23. Almand, B., Clark, J. I., Nikitina, E., van Beynen, J., English, N. R., Knight, S. C., et al. (2001). Increased production of immature myeloid cells in cancer patients: A mechanism of immunosuppression in cancer. J Immunol, 166(1), 678-689.

24. Diaz-Montero, C. M., Salem, M. L., Nishimura, M. I., Garrett-Mayer, E., Cole, D. J., \& Montero, A. J. (2009). Increased circulating myeloid-derived suppressor cells correlate with clinical cancer stage, metastatic tumor burden, and doxorubicin-cyclophosphamide chemotherapy. Cancer Immunol Immunother, 58(1), 49-59, doi:10.1007/s00262-0080523-4.

25. Sica, A., \& Bronte, V. (2007). Altered macrophage differentiation and immune dysfunction in tumor development. J Clin Invest, 117(5), 1155-1166, doi:10.1172/JCI31422.

26. Young, M. R., Kolesiak, K., Wright, M. A., \& Gabrilovich, D. I. (1999). Chemoattraction of femoral cd34+ progenitor cells by tumor-derived vascular endothelial cell growth factor. Clin Exp Metastasis, 17(10), 881-888.

27. Zea, A. H., Rodriguez, P. C., Atkins, M. B., Hernandez, C., Signoretti, S., Zabaleta, J., et al. (2005). Arginase-producing myeloid suppressor cells in renal cell carcinoma patients: A mechanism of tumor evasion. Cancer Res, 65(8), 3044-3048, doi:65/8/3044 [pii]

10.1158/0008-5472.CAN-04-4505.

28. Filipazzi, P., Valenti, R., Huber, V., Pilla, L., Canese, P., Iero, M., et al. (2007). Identification of a new subset of myeloid suppressor cells in peripheral blood of melanoma patients with modulation by a granulocyte-macrophage colony-stimulation factor-based antitumor vaccine. J Clin Oncol, 25(18), 2546-2553, doi:25/18/2546 [pii]

10.1200/JCO.2006.08.5829.

29. Hoechst, B., Ormandy, L. A., Ballmaier, M., Lehner, F., Kruger, C., Manns, M. P., et al. (2008). A new population of myeloid-derived suppressor cells in hepatocellular 
carcinoma patients induces cd4(+)cd25(+)foxp3(+) t cells. Gastroenterology, 135(1), 234243, doi:S0016-5085(08)00456-3 [pii]

10.1053/j.gastro.2008.03.020.

30. Danna, E. A., Sinha, P., Gilbert, M., Clements, V. K., Pulaski, B. A., \& Ostrand-Rosenberg, S. (2004). Surgical removal of primary tumor reverses tumor-induced immunosuppression despite the presence of metastatic disease. Cancer Res, 64(6), 22052211.

31. Serafini, P., De Santo, C., Marigo, I., Cingarlini, S., Dolcetti, L., Gallina, G., et al. (2004). Derangement of immune responses by myeloid suppressor cells. Cancer Immunol Immunother, 53(2), 64-72.

32. de Waal Malefyt, R., Yssel, H., \& de Vries, J. E. (1993). Direct effects of il-10 on subsets of human cd4+ t cell clones and resting t cells. Specific inhibition of il-2 production and proliferation. J Immunol, 150(11), 4754-4765.

33. Koch, F., Stanzl, U., Jennewein, P., Janke, K., Heufler, C., Kampgen, E., et al. (1996). High level il-12 production by murine dendritic cells: Upregulation via mhe class ii and cd40 molecules and downregulation by il-4 and il-10. J Exp Med, 184(2), 741-746.

34. Moore, K. W., de Waal Malefyt, R., Coffman, R. L., \& O'Garra, A. (2001). Interleukin-10 and the interleukin-10 receptor. Annu Rev Immunol, 19, 683-765, doi:19/1/683 [pii]

10.1146/annurev.immunol.19.1.683.

35. Bronte, V., Wang, M., Overwijk, W. W., Surman, D. R., Pericle, F., Rosenberg, S. A., et al. (1998). Apoptotic death of cd8+ t lymphocytes after immunization: Induction of a suppressive population of mac-1+/gr-1+ cells. J Immunol, 161(10), 5313-5320.

36. Gallina, G., Dolcetti, L., Serafini, P., De Santo, C., Marigo, I., Colombo, M. P., et al. (2006). Tumors induce a subset of inflammatory monocytes with immunosuppressive activity on cd8+ t cells. J Clin Invest, 116(10), 2777-2790.

37. Zea, A. H., Rodriguez, P. C., Culotta, K. S., Hernandez, C. P., DeSalvo, J., Ochoa, J. B., et al. (2004). L-arginine modulates cd3zeta expression and t cell function in activated human $\mathrm{t}$ lymphocytes. Cell Immunol, 232(1-2), 21-31.

38. De Santo, C., Serafini, P., Marigo, I., Dolcetti, L., Bolla, M., Del Soldato, P., et al. (2005). Nitroaspirin corrects immune dysfunction in tumor-bearing hosts and promotes tumor eradication by cancer vaccination. Proc Natl Acad Sci U S A, 102(11), 4185-4190.

39. Pekarek, L. A., Starr, B. A., Toledano, A. Y., \& Schreiber, H. (1995). Inhibition of tumor growth by elimination of granulocytes. $J$ Exp Med, 181(1), 435-440.

40. Stewart, T. J., Liewehr, D. J., Steinberg, S. M., Greeneltch, K. M., \& Abrams, S. I. (2009). Modulating the expression of ifn regulatory factor 8 alters the protumorigenic behavior of cd11b+gr-1+ myeloid cells. J Immunol, 183(1), 117-128, doi:jimmunol.0804132 [pii] 10.4049/jimmunol.0804132.

41. Stewart, T. J., Greeneltch, K. M., Reid, J. E., Liewehr, D. J., Steinberg, S. M., Liu, K., et al. (2009). Interferon regulatory factor- 8 modulates the development of tumour-induced cd11b+gr-1+ myeloid cells. J Cell Mol Med, 13(9B), 3939-3950, doi:JCMM685 [pii]

10.1111/j.1582-4934.2009.00685.x.

42. Kortylewski, M., Kujawski, M., Wang, T., Wei, S., Zhang, S., Pilon-Thomas, S., et al. (2005). Inhibiting stat 3 signaling in the hematopoietic system elicits multicomponent antitumor immunity. Nat Med, 11(12), 1314-1321, doi:nm1325 [pii]

$10.1038 / \mathrm{nm} 1325$.

43. Nefedova, Y., Nagaraj, S., Rosenbauer, A., Muro-Cacho, C., Sebti, S. M., \& Gabrilovich, D. I. (2005). Regulation of dendritic cell differentiation and antitumor immune response in 
cancer by pharmacologic-selective inhibition of the janus-activated kinase $2 /$ signal transducers and activators of transcription 3 pathway. Cancer Res, 65(20), 9525-9535.

44. Sinha, P., Clements, V. K., \& Ostrand-Rosenberg, S. (2005). Reduction of myeloid-derived suppressor cells and induction of $\mathrm{m} 1$ macrophages facilitate the rejection of established metastatic disease. J Immunol, 174(2), 636-645.

45. Kusmartsev, S., Cheng, F., Yu, B., Nefedova, Y., Sotomayor, E., Lush, R., et al. (2003). Alltrans-retinoic acid eliminates immature myeloid cells from tumor-bearing mice and improves the effect of vaccination. Cancer Res, 63(15), 4441-4449.

46. Young, M. R., Lozano, Y., Ihm, J., Wright, M. A., \& Prechel, M. M. (1996). Vitamin d3 treatment of tumor bearers can stimulate immune competence and reduce tumor growth when treatment coincides with a heightened presence of natural suppressor cells. Cancer Lett, 104(2), 153-161.

47. Young, M. R., \& Wright, M. A. (1992). Myelopoiesis-associated immune suppressor cells in mice bearing metastatic lewis lung carcinoma tumors: Gamma interferon plus tumor necrosis factor alpha synergistically reduces immune suppressor and tumor growthpromoting activities of bone marrow cells and diminishes tumor recurrence and metastasis. Cancer Res, 52(22), 6335-6340.

48. Mirza, N., Fishman, M., Fricke, I., Dunn, M., Neuger, A. M., Frost, T. J., et al. (2006). Alltrans-retinoic acid improves differentiation of myeloid cells and immune response in cancer patients. Cancer Res, 66(18), 9299-9307, doi:66/18/9299 [pii]

10.1158/0008-5472.CAN-06-1690.

49. Ko, J. S., Rayman, P., Ireland, J., Swaidani, S., Li, G., Bunting, K. D., et al. Direct and differential suppression of myeloid-derived suppressor cell subsets by sunitinib is compartmentally constrained. Cancer Res, 70(9), 3526-3536, doi:0008-5472.CAN-093278 [pii]

10.1158/0008-5472.CAN-09-3278.

50. Le, H. K., Graham, L., Cha, E., Morales, J. K., Manjili, M. H., \& Bear, H. D. (2009). Gemcitabine directly inhibits myeloid derived suppressor cells in balb/c mice bearing 4t1 mammary carcinoma and augments expansion of $\mathrm{t}$ cells from tumor-bearing mice. Int Immunopharmacol, 9(7-8), 900-909, doi:S1567-5769(09)00121-0 [pii]

10.1016/j.intimp.2009.03.015.

51. Ozao-Choy, J., Ma, G., Kao, J., Wang, G. X., Meseck, M., Sung, M., et al. (2009). The novel role of tyrosine kinase inhibitor in the reversal of immune suppression and modulation of tumor microenvironment for immune-based cancer therapies. Cancer Res, 69(6), 25142522, doi:0008-5472.CAN-08-4709 [pii]

10.1158/0008-5472.CAN-08-4709.

52. Suzuki, E., Kapoor, V., Jassar, A. S., Kaiser, L. R., \& Albelda, S. M. (2005). Gemcitabine selectively eliminates splenic gr-1+/cd11b+ myeloid suppressor cells in tumor-bearing animals and enhances antitumor immune activity. Clin Cancer Res, 11(18), 6713-6721.

53. Vincent, J., Mignot, G., Chalmin, F., Ladoire, S., Bruchard, M., Chevriaux, A., et al. 5fluorouracil selectively kills tumor-associated myeloid-derived suppressor cells resulting in enhanced t cell-dependent antitumor immunity. Cancer Res, 70(8), 3052-3061, doi:0008-5472.CAN-09-3690 [pii]

10.1158/0008-5472.CAN-09-3690.

54. Ko, J. S., Zea, A. H., Rini, B. I., Ireland, J. L., Elson, P., Cohen, P., et al. (2009). Sunitinib mediates reversal of myeloid-derived suppressor cell accumulation in renal cell carcinoma patients. Clin Cancer Res, 15(6), 2148-2157, doi:1078-0432.CCR-08-1332 [pii] 
10.1158/1078-0432.CCR-08-1332.

55. Fridlender, Z. G., Sun, J., Singhal, S., Kapoor, V., Cheng, G., Suzuki, E., et al. Chemotherapy delivered after viral immunogene therapy augments antitumor efficacy via multiple immune-mediated mechanisms. Mol Ther, doi:mt2010159 [pii]

$10.1038 / \mathrm{mt} .2010 .159$.

56. Godfrey, D. I., Hammond, K. J., Poulton, L. D., Smyth, M. J., \& Baxter, A. G. (2000). Nkt cells: Facts, functions and fallacies. Immunol Today, 21(11), 573-583, doi:S0167569900017357 [pii].

57. Godfrey, D. I., Stankovic, S., \& Baxter, A. G. (2010). Raising the nkt cell family. Nat Immunol, 11(3), 197-206, doi:ni.1841 [pii]

10.1038/ni.1841.

58. Smyth, M. J., Crowe, N. Y., Hayakawa, Y., Takeda, K., Yagita, H., \& Godfrey, D. I. (2002). Nkt cells - conductors of tumor immunity? Curr Opin Immunol, 14(2), 165-171, doi:S0952791502003163 [pii].

59. Smyth, M. J., \& Godfrey, D. I. (2000). Nkt cells and tumor immunity--a double-edged sword. Nat Immunol, 1(6), 459-460, doi:10.1038/82698.

60. Cerundolo, V., Silk, J. D., Masri, S. H., \& Salio, M. (2009). Harnessing invariant nkt cells in vaccination strategies. Nat Rev Immunol, 9(1), 28-38, doi:nri2451 [pii]

10.1038/nri2451.

61. Smyth, M. J., Crowe, N. Y., Pellicci, D. G., Kyparissoudis, K., Kelly, J. M., Takeda, K., et al. (2002). Sequential production of interferon-gamma by nk1.1(+) t cells and natural killer cells is essential for the antimetastatic effect of alpha-galactosylceramide. Blood, 99(4), 1259-1266.

62. Ambrosino, E., Terabe, M., Halder, R. C., Peng, J., Takaku, S., Miyake, S., et al. (2007). Cross-regulation between type $\mathrm{i}$ and type ii nkt cells in regulating tumor immunity: A new immunoregulatory axis. J Immunol, 179(8), 5126-5136, doi:179/8/5126 [pii].

63. Moodycliffe, A. M., Nghiem, D., Clydesdale, G., \& Ullrich, S. E. (2000). Immune suppression and skin cancer development: Regulation by nkt cells. Nat Immunol, 1(6), 521-525, doi:10.1038/82782.

64. Terabe, M., Khanna, C., Bose, S., Melchionda, F., Mendoza, A., Mackall, C. L., et al. (2006). Cd1d-restricted natural killer $\mathrm{t}$ cells can down-regulate tumor immunosurveillance independent of interleukin-4 receptor-signal transducer and activator of transcription 6 or transforming growth factor-beta. Cancer Res, 66(7), 3869-3875.

65. Terabe, M., Matsui, S., Noben-Trauth, N., Chen, H., Watson, C., Donaldson, D. D., et al. (2000). Nkt cell-mediated repression of tumor immunosurveillance by il-13 and the il-4rstat6 pathway. Nat Immunol, 1(6), 515-520.

66. Terabe, M., Swann, J., Ambrosino, E., Sinha, P., Takaku, S., Hayakawa, Y., et al. (2005). A nonclassical non-valpha14jalpha18 cd1d-restricted (type ii) nkt cell is sufficient for downregulation of tumor immunosurveillance. J Exp Med, 202(12), 1627-1633.

67. Park, J. M., Terabe, M., Donaldson, D. D., Forni, G., \& Berzofsky, J. A. (2008). Natural immunosurveillance against spontaneous, autochthonous breast cancers revealed and enhanced by blockade of il-13-mediated negative regulation. Cancer Immunol Immunother, 57(6), 907-912, doi:10.1007/s00262-007-0414-0.

68. Terabe, M., Matsui, S., Park, J. M., Mamura, M., Noben-Trauth, N., Donaldson, D. D., et al. (2003). Transforming growth factor-beta production and myeloid cells are an effector mechanism through which cd1d-restricted t cells block cytotoxic t lymphocyte-mediated 
tumor immunosurveillance: Abrogation prevents tumor recurrence. J Exp Med, 198(11), 1741-1752.

69. Terabe, M., Park, J. M., \& Berzofsky, J. A. (2004). Role of il-13 in regulation of anti-tumor immunity and tumor growth. Cancer Immunol Immunother, 53(2), 79-85.

70. Parmiani, G., Rivoltini, L., Andreola, G., \& Carrabba, M. (2000). Cytokines in cancer therapy. Immunol Lett, 74(1), 41-44, doi:S0165-2478(00)00247-9 [pii].

71. Stewart, T. J., \& Smyth, M. J. (2009). Chemokine-chemokine receptors in cancer immunotherapy. Immunotherapy, 1(1), 109-127, doi:10.2217/1750743X.1.1.109.

72. Gorelik, L., \& Flavell, R. A. (2002). Transforming growth factor-beta in t-cell biology. Nat Rev Immunol, 2(1), 46-53, doi:10.1038/nri704.

73. Letterio, J. J., \& Roberts, A. B. (1998). Regulation of immune responses by tgf-beta. Annu Rev Immunol, 16, 137-161, doi:10.1146/annurev.immunol.16.1.137.

74. Li, M. O., \& Flavell, R. A. (2008). Tgf-beta: A master of all t cell trades. Cell, 134(3), 392404, doi:S0092-8674(08)00945-8 [pii]

10.1016/j.cell.2008.07.025.

75. Borkowski, T. A., Letterio, J. J., Farr, A. G., \& Udey, M. C. (1996). A role for endogenous transforming growth factor beta 1 in langerhans cell biology: The skin of transforming growth factor beta 1 null mice is devoid of epidermal langerhans cells. J Exp Med, 184(6), 2417-2422.

76. Geissmann, F., Revy, P., Regnault, A., Lepelletier, Y., Dy, M., Brousse, N., et al. (1999). Tgf-beta 1 prevents the noncognate maturation of human dendritic langerhans cells. $J$ Immunol, 162(8), 4567-4575.

77. Bierie, B., \& Moses, H. L. (2006). Tumour microenvironment: Tgfbeta: The molecular jekyll and hyde of cancer. Nat Rev Cancer, 6(7), 506-520, doi:nrc1926 [pii]

10.1038/nrc1926.

78. Takaku, S., Terabe, M., Ambrosino, E., Peng, J., Lonning, S., McPherson, J. M., et al. Blockade of tgf-beta enhances tumor vaccine efficacy mediated by cd8(+) t cells. Int $J$ Cancer, 126(7), 1666-1674, doi:10.1002/ijc.24961.

79. Terabe, M., Ambrosino, E., Takaku, S., O'Konek, J. J., Venzon, D., Lonning, S., et al. (2009). Synergistic enhancement of cd8+ $t$ cell-mediated tumor vaccine efficacy by an antitransforming growth factor-beta monoclonal antibody. Clin Cancer Res, 15(21), 65606569, doi:1078-0432.CCR-09-1066 [pii]

10.1158/1078-0432.CCR-09-1066.

80. Ueda, R., Fujita, M., Zhu, X., Sasaki, K., Kastenhuber, E. R., Kohanbash, G., et al. (2009). Systemic inhibition of transforming growth factor-beta in glioma-bearing mice improves the therapeutic efficacy of glioma-associated antigen peptide vaccines. Clin Cancer Res, 15(21), 6551-6559, doi:1078-0432.CCR-09-1067 [pii]

10.1158/1078-0432.CCR-09-1067.

81. Nagaraj, N. S., \& Datta, P. K. Targeting the transforming growth factor-beta signaling pathway in human cancer. Expert Opin Investig Drugs, 19(1), 77-91, doi:10.1517/13543780903382609.

82. Uhl, M., Aulwurm, S., Wischhusen, J., Weiler, M., Ma, J. Y., Almirez, R., et al. (2004). Sd208, a novel transforming growth factor beta receptor i kinase inhibitor, inhibits growth and invasiveness and enhances immunogenicity of murine and human glioma cells in vitro and in vivo. Cancer Res, 64(21), 7954-7961, doi:64/21/7954 [pii]

10.1158/0008-5472.CAN-04-1013. 
83. Hau, P., Jachimczak, P., \& Bogdahn, U. (2009). Treatment of malignant gliomas with tgfbeta2 antisense oligonucleotides. Expert Rev Anticancer Ther, 9(11), 1663-1674, doi:10.1586/era.09.138.

84. Hau, P., Jachimczak, P., Schlingensiepen, R., Schulmeyer, F., Jauch, T., Steinbrecher, A., et al. (2007). Inhibition of tgf-beta2 with ap 12009 in recurrent malignant gliomas: From preclinical to phase i/ii studies. Oligonucleotides, 17(2), 201-212, doi:10.1089/oli.2006.0053.

85. Nemunaitis, J., Nemunaitis, M., Senzer, N., Snitz, P., Bedell, C., Kumar, P., et al. (2009). Phase ii trial of belagenpumatucel-1, a tgf-beta2 antisense gene modified allogeneic tumor vaccine in advanced non small cell lung cancer (nsclc) patients. Cancer Gene Ther, 16(8), 620-624, doi:cgt200915 [pii]

10.1038/cgt.2009.15.

86. Vicari, A. P., \& Trinchieri, G. (2004). Interleukin-10 in viral diseases and cancer: Exiting the labyrinth? Immunol Rev, 202, 223-236, doi:IMR216 [pii]

10.1111/j.0105-2896.2004.00216.x.

87. Bagri, A., Kouros-Mehr, H., Leong, K. G., \& Plowman, G. D. Use of anti-vegf adjuvant therapy in cancer: Challenges and rationale. Trends Mol Med, 16(3), 122-132, doi:S14714914(10)00010-9 [pii]

10.1016/j.molmed.2010.01.004.

88. Johnson, B., Osada, T., Clay, T., Lyerly, H., \& Morse, M. (2009). Physiology and therapeutics of vascular endothelial growth factor in tumor immunosuppression. Curr Mol Med, 9(6), 702-707.

89. Gabrilovich, D. I., Ishida, T., Nadaf, S., Ohm, J. E., \& Carbone, D. P. (1999). Antibodies to vascular endothelial growth factor enhance the efficacy of cancer immunotherapy by improving endogenous dendritic cell function. Clin Cancer Res, 5(10), 2963-2970.

90. Alfaro, C., Suarez, N., Gonzalez, A., Solano, S., Erro, L., Dubrot, J., et al. (2009). Influence of bevacizumab, sunitinib and sorafenib as single agents or in combination on the inhibitory effects of vegf on human dendritic cell differentiation from monocytes. $\mathrm{Br} J$ Cancer, 100(7), 1111-1119, doi:6604965 [pii]

10.1038/sj.bjc.6604965.

91. Li, B., Lalani, A. S., Harding, T. C., Luan, B., Koprivnikar, K., Huan Tu, G., et al. (2006). Vascular endothelial growth factor blockade reduces intratumoral regulatory t cells and enhances the efficacy of a gm-csf-secreting cancer immunotherapy. Clin Cancer Res, 12(22), 6808-6816, doi:12/22/6808 [pii]

10.1158/1078-0432.CCR-06-1558.

92. Osada, T., Chong, G., Tansik, R., Hong, T., Spector, N., Kumar, R., et al. (2008). The effect of anti-vegf therapy on immature myeloid cell and dendritic cells in cancer patients. Cancer Immunol Immunother, 57(8), 1115-1124, doi:10.1007/s00262-007-0441-x.

93. Rini, B. I., Weinberg, V., Fong, L., Conry, S., Hershberg, R. M., \& Small, E. J. (2006). Combination immunotherapy with prostatic acid phosphatase pulsed antigen-presenting cells (provenge) plus bevacizumab in patients with serologic progression of prostate cancer after definitive local therapy. Cancer, 107(1), 67-74, doi:10.1002/cncr.21956.

94. Conti, I., \& Rollins, B. J. (2004). Ccl2 (monocyte chemoattractant protein-1) and cancer. Semin Cancer Biol, 14(3), 149-154.

95. Hasegawa, H., Inoue, A., Muraoka, M., Yamanouchi, J., Miyazaki, T., \& Yasukawa, M. (2007). Therapy for pneumonitis and sialadenitis by accumulation of ccr2-expressing 
cd4+cd25+ regulatory t cells in mrl/lpr mice. Arthritis Res Ther, 9(1), R15, doi:ar2122 [pii]

$10.1186 / \operatorname{ar} 2122$.

96. Hu, K., Xiong, J., Ji, K., Sun, H., Wang, J., \& Liu, H. (2007). Recombined cc chemokine ligand 2 into b16 cells induces production of th2-dominant [correction of dominanted] cytokines and inhibits melanoma metastasis. Immunol Lett, 113(1), 19-28, doi:S01652478(07)00147-2 [pii]

10.1016/j.imlet.2007.07.004.

97. Peng, L., Shu, S., \& Krauss, J. C. (1997). Monocyte chemoattractant protein inhibits the generation of tumor-reactive t cells. Cancer Res, 57(21), 4849-4854.

98. Ueno, T., Toi, M., Saji, H., Muta, M., Bando, H., Kuroi, K., et al. (2000). Significance of macrophage chemoattractant protein-1 in macrophage recruitment, angiogenesis, and survival in human breast cancer. Clin Cancer Res, 6(8), 3282-3289.

99. Jordan, J. T., Sun, W., Hussain, S. F., DeAngulo, G., Prabhu, S. S., \& Heimberger, A. B. (2008). Preferential migration of regulatory t cells mediated by glioma-secreted chemokines can be blocked with chemotherapy. Cancer Immunol Immunother, 57(1), 123-131, doi:10.1007/s00262-007-0336-x.

100. Pollard, J. W. (2004). Tumour-educated macrophages promote tumour progression and metastasis. Nat Rev Cancer, 4(1), 71-78, doi:10.1038/nrc1256

nrc1256 [pii].

101. Loberg, R. D., Ying, C., Craig, M., Day, L. L., Sargent, E., Neeley, C., et al. (2007). Targeting ccl 2 with systemic delivery of neutralizing antibodies induces prostate cancer tumor regression in vivo. Cancer Res, 67(19), 9417-9424.

102. Loberg, R. D., Ying, C., Craig, M., Yan, L., Snyder, L. A., \& Pienta, K. J. (2007). Ccl2 as an important mediator of prostate cancer growth in vivo through the regulation of macrophage infiltration. Neoplasia, 9(7), 556-562.

103. Fridlender, Z. G., Buchlis, G., Kapoor, V., Cheng, G., Sun, J., Singhal, S., et al. Ccl2 blockade augments cancer immunotherapy. Cancer Res, 70(1), 109-118, doi:00085472.CAN-09-2326 [pii]

10.1158/0008-5472.CAN-09-2326.

104. Li, J. H., Rosen, D., Sondel, P., \& Berke, G. (2002). Immune privilege and fasl: Two ways to inactivate effector cytotoxic t lymphocytes by fasl-expressing cells. Immunology, 105(3), 267-277.

105. Schwartz, R. H. (2003). T cell anergy. Annu Rev Immunol, 21, 305-334, doi:10.1146/annurev.immunol.21.120601.141110

120601.141110 [pii].

106. Greiner, J. W., Zeytin, H., Anver, M. R., \& Schlom, J. (2002). Vaccine-based therapy directed against carcinoembryonic antigen demonstrates antitumor activity on spontaneous intestinal tumors in the absence of autoimmunity. Cancer Res, 62(23), 69446951.

107. Eder, J. P., Kantoff, P. W., Roper, K., Xu, G. X., Bubley, G. J., Boyden, J., et al. (2000). A phase $\mathrm{i}$ trial of a recombinant vaccinia virus expressing prostate-specific antigen in advanced prostate cancer. Clin Cancer Res, 6(5), 1632-1638.

108. Marshall, J. L., Gulley, J. L., Arlen, P. M., Beetham, P. K., Tsang, K. Y., Slack, R., et al. (2005). Phase i study of sequential vaccinations with fowlpox-cea(6d)-tricom alone and sequentially with vaccinia-cea(6d)-tricom, with and without granulocyte-macrophage 
colony-stimulating factor, in patients with carcinoembryonic antigen-expressing carcinomas. J Clin Oncol, 23(4), 720-731, doi:JCO.2005.10.206 [pii]

10.1200/JCO.2005.10.206.

109. Frey, A. B., \& Monu, N. (2008). Signaling defects in anti-tumor t cells. Immunol Rev, 222, 192-205, doi:IMR606 [pii]

10.1111/j.1600-065X.2008.00606.x.

110. Whiteside, T. L. Immune responses to malignancies. J Allergy Clin Immunol, 125(2 Suppl 2), S272-283, doi:S0091-6749(09)01464-X [pii]

10.1016/j.jaci.2009.09.045.

111. Egen, J. G., Kuhns, M. S., \& Allison, J. P. (2002). Ctla-4: New insights into its biological function and use in tumor immunotherapy. Nat Immunol, 3(7), 611-618.

112. Boasso, A., Herbeuval, J. P., Hardy, A. W., Winkler, C., \& Shearer, G. M. (2005).

Regulation of indoleamine 2,3-dioxygenase and tryptophanyl-trna-synthetase by ctla-4-fc in human cd4+ t cells. Blood, 105(4), 1574-1581, doi:2004-06-2089 [pii]

10.1182/blood-2004-06-2089.

113. Mangsbo, S. M., Sandin, L. C., Anger, K., Korman, A. J., Loskog, A., \& Totterman, T. H. Enhanced tumor eradication by combining ctla-4 or pd-1 blockade with cpg therapy. $J$ Immunother, 33(3), 225-235, doi:10.1097/CJI.0b013e3181c01fcb

00002371-201004000-00001 [pii].

114. Takeda, K., Kojima, Y., Uno, T., Hayakawa, Y., Teng, M. W., Yoshizawa, H., et al. Combination therapy of established tumors by antibodies targeting immune activating and suppressing molecules. J Immunol, 184(10), 5493-5501, doi:jimmunol.0903033 [pii] 10.4049/jimmunol.0903033.

115. Sarnaik, A. A., \& Weber, J. S. (2009). Recent advances using anti-ctla-4 for the treatment of melanoma. Cancer J, 15(3), 169-173, doi:10.1097/PPO.0b013e3181a7450f

00130404-200906000-00001 [pii].

116. Agarwala, S. S. Novel immunotherapies as potential therapeutic partners for traditional or targeted agents: Cytotoxic t-lymphocyte antigen-4 blockade in advanced melanoma. Melanoma Res, 20(1), 1-10, doi:10.1097/CMR.0b013e328333bbc8.

117. Page, D. B., Yuan, J., \& Wolchok, J. D. Targeting cytotoxic t-lymphocyte antigen 4 in immunotherapies for melanoma and other cancers. Immunotherapy, 2(3), 367-379, doi:10.2217/imt.10.21.

118. Weber, J. S. (2006). The clinical utility of cytotoxic t lymphocyte antigen 4 abrogation by human antibodies. Melanoma Res, 16(5), 379-383, doi:10.1097/01.cmr.0000232292.06785.a3

00008390-200610000-00002 [pii].

119. Dong, H., Strome, S. E., Salomao, D. R., Tamura, H., Hirano, F., Flies, D. B., et al. (2002). Tumor-associated b7-h1 promotes t-cell apoptosis: A potential mechanism of immune evasion. Nat Med, 8(8), 793-800.

120. Fourcade, J., Kudela, P., Sun, Z., Shen, H., Land, S. R., Lenzner, D., et al. (2009). Pd-1 is a regulator of ny-eso-1-specific cd8+ t cell expansion in melanoma patients. J Immunol, 182(9), 5240-5249, doi:182/9/5240 [pii]

10.4049/jimmunol.0803245.

121. Matsuzaki, J., Gnjatic, S., Mhawech-Fauceglia, P., Beck, A., Miller, A., Tsuji, T., et al. Tumor-infiltrating ny-eso-1-specific cd8+t cells are negatively regulated by lag-3 and pd1 in human ovarian cancer. Proc Natl Acad Sci U S A, 107(17), 7875-7880, doi:1003345107 [pii] 
10.1073/pnas.1003345107.

122. Fourcade, J., Sun, Z., Benallaoua, M., Guillaume, P., Luescher, I. F., Sander, C., et al.

Upregulation of tim-3 and pd-1 expression is associated with tumor antigen-specific cd8+ t cell dysfunction in melanoma patients. J Exp Med, doi:jem.20100637 [pii]

10.1084/jem.20100637.

123. Ichikawa, M., \& Chen, L. (2005). Role of b7-h1 and b7-h4 molecules in down-regulating effector phase of t-cell immunity: Novel cancer escaping mechanisms. Front Biosci, 10, 2856-2860.

124. Wang, W., Lau, R., Yu, D., Zhu, W., Korman, A., \& Weber, J. (2009). Pd1 blockade reverses the suppression of melanoma antigen-specific ctl by cd4+ cd25(hi) regulatory $\mathrm{t}$ cells. Int Immunol, 21(9), 1065-1077, doi:dxp072 [pii]

10.1093/intimm/dxp072.

125. Curiel, T. J., Wei, S., Dong, H., Alvarez, X., Cheng, P., Mottram, P., et al. (2003). Blockade of b7-h1 improves myeloid dendritic cell-mediated antitumor immunity. Nat Med, 9(5), 562-567, doi:10.1038/nm863

nm863 [pii].

126. Brahmer, J. R., Drake, C. G., Wollner, I., Powderly, J. D., Picus, J., Sharfman, W. H., et al. Phase i study of single-agent anti-programmed death-1 (mdx-1106) in refractory solid tumors: Safety, clinical activity, pharmacodynamics, and immunologic correlates. J Clin Oncol, 28(19), 3167-3175, doi:JCO.2009.26.7609 [pii]

10.1200/JCO.2009.26.7609.

127. Li, P., Yin, Y. L., Li, D., Kim, S. W., \& Wu, G. (2007). Amino acids and immune function. Br J Nutr, 98(2), 237-252, doi:S000711450769936X [pii]

$10.1017 / \mathrm{S} 000711450769936 \mathrm{X}$.

128. Bronte, V., \& Zanovello, P. (2005). Regulation of immune responses by l-arginine metabolism. Nat Rev Immunol, 5(8), 641-654.

129. Mocellin, S., Bronte, V., \& Nitti, D. (2007). Nitric oxide, a double edged sword in cancer biology: Searching for therapeutic opportunities. Med Res Rev, 27(3), 317-352, doi:10.1002/med.20092.

130. Rodriguez, P. C., Quiceno, D. G., Zabaleta, J., Ortiz, B., Zea, A. H., Piazuelo, M. B., et al. (2004). Arginase i production in the tumor microenvironment by mature myeloid cells inhibits t-cell receptor expression and antigen-specific t-cell responses. Cancer Res, 64(16), 5839-5849.

131. Bronte, V., Kasic, T., Gri, G., Gallana, K., Borsellino, G., Marigo, I., et al. (2005). Boosting antitumor responses of t lymphocytes infiltrating human prostate cancers. $J$ Exp Med, 201(8), 1257-1268.

132. Stagg, J., \& Smyth, M. J. Extracellular adenosine triphosphate and adenosine in cancer. Oncogene, doi:onc2010292 [pii]

10.1038/onc.2010.292.

133. Mandapathil, M., Hilldorfer, B., Szczepanski, M. J., Czystowska, M., Szajnik, M., Ren, J., et al. Generation and accumulation of immunosuppressive adenosine by human cd4+cd25highfoxp3+ regulatory t cells. J Biol Chem, 285(10), 7176-7186, doi:M109.047423 [pii]

10.1074/jbc.M109.047423.

134. Jin, D., Fan, J., Wang, L., Thompson, L. F., Liu, A., Daniel, B. J., et al. Cd73 on tumor cells impairs antitumor t-cell responses: A novel mechanism of tumor-induced immune suppression. Cancer Res, 70(6), 2245-2255, doi:0008-5472.CAN-09-3109 [pii] 
10.1158/0008-5472.CAN-09-3109.

135. Takedachi, M., Qu, D., Ebisuno, Y., Oohara, H., Joachims, M. L., McGee, S. T., et al. (2008). Cd73-generated adenosine restricts lymphocyte migration into draining lymph nodes. J Immunol, 180(9), 6288-6296, doi:180/9/6288 [pii].

136. Stagg, J., Divisekera, U., McLaughlin, N., Sharkey, J., Pommey, S., Denoyer, D., et al. Anticd73 antibody therapy inhibits breast tumor growth and metastasis. Proc Natl Acad Sci U $S$ A, 107(4), 1547-1552, doi:0908801107 [pii]

10.1073/pnas.0908801107.

137. Uyttenhove, C., Pilotte, L., Theate, I., Stroobant, V., Colau, D., Parmentier, N., et al. (2003). Evidence for a tumoral immune resistance mechanism based on tryptophan degradation by indoleamine 2,3-dioxygenase. Nat Med, 9(10), 1269-1274, doi:10.1038/nm934 nm934 [pii].

138. Liu, X., Newton, R. C., Friedman, S. M., \& Scherle, P. A. (2009). Indoleamine 2,3dioxygenase, an emerging target for anti-cancer therapy. Curr Cancer Drug Targets, 9(8), 938-952.

139. Lob, S., Konigsrainer, A., Rammensee, H. G., Opelz, G., \& Terness, P. (2009). Inhibitors of indoleamine-2,3-dioxygenase for cancer therapy: Can we see the wood for the trees? Nat Rev Cancer, 9(6), 445-452, doi:nrc2639 [pii]

10.1038/nrc2639.

140. Munn, D. H., Zhou, M., Attwood, J. T., Bondarev, I., Conway, S. J., Marshall, B., et al. (1998). Prevention of allogeneic fetal rejection by tryptophan catabolism. Science, 281(5380), 1191-1193.

141. Grohmann, U., Orabona, C., Fallarino, F., Vacca, C., Calcinaro, F., Falorni, A., et al. (2002). Ctla-4-ig regulates tryptophan catabolism in vivo. Nat Immunol, 3(11), 1097-1101, doi:10.1038/ni846

ni846 [pii].

142. Munn, D. H., Sharma, M. D., Hou, D., Baban, B., Lee, J. R., Antonia, S. J., et al. (2004). Expression of indoleamine 2,3-dioxygenase by plasmacytoid dendritic cells in tumordraining lymph nodes. J Clin Invest, 114(2), 280-290, doi:10.1172/JCI21583.

143. Munn, D. H., \& Mellor, A. L. (2007). Indoleamine 2,3-dioxygenase and tumor-induced tolerance. J Clin Invest, 117(5), 1147-1154, doi:10.1172/JCI31178.

144. Muller, A. J., \& Prendergast, G. C. (2007). Indoleamine 2,3-dioxygenase in immune suppression and cancer. Curr Cancer Drug Targets, 7(1), 31-40.

145. Muller, A. J., DuHadaway, J. B., Donover, P. S., Sutanto-Ward, E., \& Prendergast, G. C. (2005). Inhibition of indoleamine 2,3-dioxygenase, an immunoregulatory target of the cancer suppression gene bin1, potentiates cancer chemotherapy. Nat Med, 11(3), 312-319, doi:nm1196 [pii]

10.1038/nm1196.

146. Wang, M. T., Honn, K. V., \& Nie, D. (2007). Cyclooxygenases, prostanoids, and tumor progression. Cancer Metastasis Rev, 26(3-4), 525-534, doi:10.1007/s10555-007-9096-5.

147. Gasparini, G., Longo, R., Sarmiento, R., \& Morabito, A. (2003). Inhibitors of cyclooxygenase 2: A new class of anticancer agents? Lancet Oncol, 4(10), 605-615, doi:S1470204503012208 [pii].

148. Sarkar, F. H., Adsule, S., Li, Y., \& Padhye, S. (2007). Back to the future: Cox-2 inhibitors for chemoprevention and cancer therapy. Mini Rev Med Chem, 7(6), 599-608.

149. Greenhough, A., Smartt, H. J., Moore, A. E., Roberts, H. R., Williams, A. C., Paraskeva, C., et al. (2009). The cox-2/pge2 pathway: Key roles in the hallmarks of cancer and 
adaptation to the tumour microenvironment. Carcinogenesis, 30(3), 377-386, doi:bgp014 [pii]

10.1093/carcin/bgp014.

150. Harris, S. G., Padilla, J., Koumas, L., Ray, D., \& Phipps, R. P. (2002). Prostaglandins as modulators of immunity. Trends Immunol, 23(3), 144-150, doi:S1471490601021548 [pii].

151. Pockaj, B. A., Basu, G. D., Pathangey, L. B., Gray, R. J., Hernandez, J. L., Gendler, S. J., et al. (2004). Reduced t-cell and dendritic cell function is related to cyclooxygenase-2 overexpression and prostaglandin e2 secretion in patients with breast cancer. Ann Surg Oncol, 11(3), 328-339.

152. Sharma, S., Yang, S. C., Zhu, L., Reckamp, K., Gardner, B., Baratelli, F., et al. (2005). Tumor cyclooxygenase-2/prostaglandin e2-dependent promotion of foxp3 expression and cd4+ cd25+t regulatory cell activities in lung cancer. Cancer Res, 65(12), 5211-5220, doi:65/12/5211 [pii]

10.1158/0008-5472.CAN-05-0141.

153. Stolina, M., Sharma, S., Lin, Y., Dohadwala, M., Gardner, B., Luo, J., et al. (2000). Specific inhibition of cyclooxygenase 2 restores antitumor reactivity by altering the balance of il10 and il-12 synthesis. J Immunol, 164(1), 361-370, doi:ji_v164n1p361 [pii].

154. Basu, G. D., Tinder, T. L., Bradley, J. M., Tu, T., Hattrup, C. L., Pockaj, B. A., et al. (2006). Cyclooxygenase-2 inhibitor enhances the efficacy of a breast cancer vaccine: Role of ido. J Immunol, 177(4), 2391-2402, doi:177/4/2391 [pii].

155. Zeytin, H. E., Patel, A. C., Rogers, C. J., Canter, D., Hursting, S. D., Schlom, J., et al. (2004). Combination of a poxvirus-based vaccine with a cyclooxygenase-2 inhibitor (celecoxib) elicits antitumor immunity and long-term survival in cea. $\mathrm{Tg} / \mathrm{min}$ mice. Cancer Res, 64(10), 3668-3678, doi:10.1158/0008-5472.CAN-03-3878

64/10/3668 [pii].

156. Csiki, I., Morrow, J. D., Sandler, A., Shyr, Y., Oates, J., Williams, M. K., et al. (2005). Targeting cyclooxygenase- 2 in recurrent non-small cell lung cancer: A phase ii trial of celecoxib and docetaxel. Clin Cancer Res, 11(18), 6634-6640, doi:11/18/6634 [pii]

10.1158/1078-0432.CCR-05-0436.

157. Ferrari, V., Valcamonico, F., Amoroso, V., Simoncini, E., Vassalli, L., Marpicati, P., et al. (2006). Gemcitabine plus celecoxib (geco) in advanced pancreatic cancer: A phase ii trial. Cancer Chemother Pharmacol, 57(2), 185-190, doi:10.1007/s00280-005-0028-1. 
Table 1: Methods of "suppressing the suppressors."

\begin{tabular}{|c|c|c|}
\hline \multicolumn{3}{|c|}{ Regulatory cells } \\
\hline \multirow[t]{5}{*}{ MDSC } & Inhibit their accumulation & Upregulate IRF-8; possibly reduce STAT-3/6 \\
\hline & & Reduce the production of inducing TDF eg. GM-CSF, CSF-1, VEGF \\
\hline & & antibodies. Lymphoablation (chemical or radiation). \\
\hline & - chemotherapies & Eg. Gemcitabine, sunitinib, 5FU \\
\hline & Inhibit their suppressive mechanisms & Arginase, NOS, ROS, IL-10 (See below) \\
\hline \multirow[t]{3}{*}{ Treg } & Reduce their numbers & mAbs eg. Daclizumab (anti-CD25) \\
\hline & & Immunotoxin eg. Ontak ${ }^{\mathrm{TM}}$ (denileukin diftitox) \\
\hline & & Lymphoablation (chemical or radiation) \\
\hline NKT & Inhibit their suppressive mechanisms & IL-13?, TGF- $\beta$ ?, neutralize CD1d \\
\hline \multicolumn{3}{|c|}{ Cytokines/Chemokines } \\
\hline \multirow[t]{2}{*}{ IL-10 } & Reduce IL-10 levels; inhibit signaling & mAbs against IL-10 or its receptor \\
\hline & Inhibit the cells producing IL-10 & Reduce the numbers of MDSC, TAMs etc. \\
\hline \multirow[t]{3}{*}{ TGF- $\beta$} & Reduce TGF- $\beta$ levels; inhibit signaling & mAbs eg. Infliximab, Lerdelimumab, GC-1008 \\
\hline & & Small molecule inhibitors \\
\hline & & Antisense oligodeoxynucleotides eg. trabedersen \\
\hline VEGF & Reduce VEGF levels & mAbs eg. bevacizumab \\
\hline
\end{tabular}




\section{CCL2}

Reduce CCL2 levels; inhibit signaling

Inhibit the cells producing CCL2

Exhaustion

CTLA-4

PD-1 / PD-L1

Inhibit signaling

Inhibit signaling

Metabolic

Arginase I

Nitric oxide synthase

Inhibit enzymatic activity

Inhibit the cells producing arginase I

Inhibit enzymatic activity

Inhibit the cells producing NOS

Adenosine

Ectonucleotidase inhibitors

Inhibit signaling

IDO

Inhibit enzymatic activity

Inhibit the cells producing IDO

Neutralize its toxic metabolites

COX2

$\mathrm{PGE}_{2}$
Inhibit enzymatic activity

Inhibit signaling
mAbs against CCL2 or its receptors

Reduce the numbers of MDSC, TAMs etc.

mAbs eg. Ipilimumab, Tremelimumab

mAbs against PD-L1 or PD-1 eg.MDX-1106

PD-1 decoy receptors

L-arginine analogues eg. Nor-NOHA, nitroaspirin

Reduce the numbers of MDSC, TAMs etc.

L-arginine analogues eg. 1-NMMA, nitroaspirin

Reduce the numbers of MDSC, TAMs etc.

mAbs against $\mathrm{CD} 73$ or $\mathrm{CD} 39$

Adenosine receptor antagonists, small molecule inhibitors

Small molecule inhibitors eg. 1MT, d-1-MT

IDO-specific siRNA, inhibit $\mathrm{PGE}_{2}$

Natural products eg. Brassinin, exiguamine

Reduce the numbers of DCs, macrophages etc.

mAbs against $\mathrm{N}$-formyl-kynurenine

COX2 inhibitors eg. Celecoxib, rofecoxib

Receptor blockade

Myeloid-derived suppressor cells (MDSC); tumor-derived factors (TDF); tumor-associated macrophages (TAM); dendritic cell (DC); monoclonal antibodies (mAbs) 